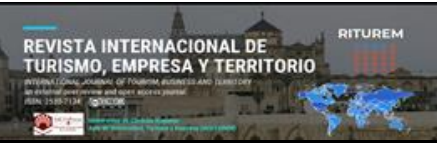

Cita bibliográfica: Hernández Flores, Y; Sánchez Borges, Y.; Saldiña Silvera, B. y Rives González, K.A. (2020). Características de la demanda potencial del destino Cuba en la nueva normalidad postcoronavirus. Revista Internacional de Turismo, Empresa y Territorio, 4 (2), 158-177. https://doi.org/10.21071/riturem.v4i2.13050

\title{
Características de la demanda potencial del destino Cuba en la nueva normalidad postcoronavirus
}

\section{Characteristic of potential demand to Cuba'destiny in the new normality post Covid 19}

\author{
Yoan Hernández Flores *1 \\ Yennifer Sánchez Borges ${ }^{2}$ \\ Bismario Saldiña Silvera ${ }^{3}$ \\ Karla Ananda Rives González ${ }^{4}$
}

\begin{abstract}
Resumen
La pandemia generada por el virus SARS-CoV-2 ha provocado graves afectaciones al sector del turismo, influyendo, a gran escala, la gran incertidumbre en los visitantes internacionales a la hora de realizar viajes en el contexto de la nueva realidad. La presente investigación surge ante la necesidad de realizar estudios sobre las preferencias de los viajeros, que en una "normalidad", puedan arribar al destino Cuba para de esta forma ser capaz de brindar un servicio de calidad. Por ello se propone como objetivo general caracterizar la demanda potencial al destino Cuba en la nueva normalidad. Se aplicaron los métodos análisis-síntesis e histórico-lógico como métodos teóricos, así como el análisis documental como método empírico. Como principales resultados se identificaron los cambios previsibles en la demanda turística hacia Cuba, relacionadas fundamentalmente, con la decisión de viaje, fecha oportuna, motivaciones, vías de obtención de información, formas de organización del viaje, duración promedio del mismo, así como con las prioridades y medidas de prevención ante el riesgo de contagio.
\end{abstract}

Palabras clave: turismo, demanda turística potencial, nueva normalidad, post Covid 19, Cuba.

\begin{abstract}
The pandemic generated by the SARS-CoV-2 virus has seriously affected the tourism sector, influencing, on a large scale, the great uncertainty in international visitors when making trips in the

\footnotetext{
${ }^{1}$ Docente de la Facultad de Turismo, Universidad de La Habana, Cuba. yoan961122@gmail.com. Id orcid http://orcid.org/0000-0003-1935-2594 * Autor para la correspondencia

${ }^{2}$ Docente de la Facultad de Turismo, Universidad de La Habana, Cuba. ysanchezb97@gmail.com. Id orcid http://orcid.org/0000-0002-0455-2000

3 Investigador en formación de la Facultad de Turismo, Universidad de La Habana, Cuba. sardinasbismario@gmail.com Id orcid http://orcid.org/0000-0003-4445-236X

4 Investigadora en formación de la Facultad de Turismo, Universidad de La Habana, Cuba. karla.rives1999@gmail.com
} 
context of the new reality. This research arises from the need to carry out studies about the preferences of travelers, who in a "normality", can arrive at the Cuban destination in order to be able to provide a quality service. Therefore, it is proposed as a general objective: to characterize the potential demand to Cuba destination in the new normal. Analysis-synthesis and historical-logical methods were applied as theoretical methods, as well as documentary analysis as an empirical method. The main results were the foreseeable changes in tourist demand to Cuba, mainly related to the decision to travel, the appropriate date, motivations, ways of organizing the trip, average duration of the trip, as well as the priorities and prevention measures against the contagion risk.

Keywords: tourism, potential touristic demand, new normality, post Covid 19, Cuba.

\section{Introducción}

Las empresas tienen el reto de estudiar el futuro por la complejidad del contexto decisional, caracterizado por la incertidumbre, inestabilidad, inexactitud de la información y alto nivel de conflicto; así como por la necesidad de contar con pronósticos expertos sobre el futuro, para tomar decisiones estratégicas (Hernández, Rodríguez y Ayala, 2020).

Precisamente, el entorno del turismo ha cambiado desde que la COVID-19 (Coronavirus Disease 2019), enfermedad provocada por el virus SARS-CoV-2 fue declarada pandemia global por la Organización Mundial de la Salud (OMS) el 11 de marzo de 2020.

Según Rodríguez (2020), citado en González et al. (2020), la propagación de la pandemia de la COVID-19 ha sumido a la humanidad en una angustiosa tragedia. La pérdida de vidas humanas, el colapso de sistemas sanitarios, la ansiedad de las personas, la incertidumbre sobre la erradicación y el impacto sobre la economía mundial han sido algunas de las diversas consecuencias resultado de la propagación del virus.

Frente a pronósticos y variables sobre una posible recuperación del sector, resulta muy difícil acercarlos a la realidad pues el mundo se encuentra en estado de conmoción tras el impacto psicológico y sociológico del confinamiento, factores claves para predecir futuros escenarios en el turismo. A pesar de ello, las predicciones de la Organización Mundial del Turismo (OMT) y de la Empresa Global Journey Consulting valoran diferentes escenarios basados en algoritmos de probabilidades, que lo sitúan en el corto plazo, con signos de recuperación en el último trimestre de 2020, pero sobre todo en 2021 (Rodríguez, 2020).

Por una parte, Higgins-Desbiolles (2020) considera que la pandemia del COVID-19, impulsa la reflexión entre los empresarios para pensar un turismo socialmente responsable, que considere, más allá de las ganancias propias, proteger a las comunidades, a ello se suma que en la etapa post COVID-19, las dinámicas de consumo habrán cambiado instigadas por la desconfianza, la austeridad y la incertidumbre; variables que seguirán influenciando la toma de decisiones del consumidor, especialmente en las lógicas de los viajeros.

En Cuba, el desarrollo que gradualmente ha alcanzado el turismo, lo ha convertido en uno de los sectores más importantes de la economía del país, una sólida fuente de ingresos en divisas, así como un sector que dispone de posibilidades para fortalecer otras actividades financieras, por lo cual, en este nuevo escenario del 2020, la isla ha sufrido cuantiosas pérdidas económicas vinculadas con las medidas restrictivas tomadas durante varios meses. 
Precisamente Cuba, donde el primer caso de COVID-19 fue detectado el 11 de marzo del 2020, ha reaccionado a la epidemia y elaborado respuestas desde mucho antes. En ellas, "se aprecia el esfuerzo temprano por articular la gestión gubernamental con la gestión científica y tecnológica y el conocimiento experto" (Díaz-Canel y Núñez, 2020).

Cuando el día 16 de octubre de 2020, el ministro de transporte, anunciara la apertura de todos los aeropuertos del país, con excepción de La Habana, permitiendo con ello la entrada de cubanos y extranjeros a la isla bajo estrictas medidas de seguridad en las instalaciones, se realizaba un llamado además hacia la apertura gradual de las actividades vinculadas con el sector del turismo.

Es por ello, que se hace necesario conocer las preferencias de esos visitantes, que en una "normalidad" arribarán al destino Cuba, en aras de facilitar a los gestores información valiosa, la cual se pueda tener en cuenta para modificar, y mejorar en la prestación de servicios, y en el diseño de nuevos productos turísticos.

Ante esta situación, se realiza la presente investigación, la cual tiene como objetivo general: Caracterizar la demanda potencial al destino Cuba en la nueva normalidad.

\section{Metodología}

La investigación realizada de acuerdo con Hernández, Fernández y Baptista (2014), se clasifica como descriptiva, pues en esta se describe los cambios ocurridos en la demanda a nivel internacional en períodos post COVID-19. Además, es clasificada como de naturaleza cuantitativa y cualitativa, pues se utilizan también análisis matemáticos y descripciones cualitativas.

Dentro de los métodos teóricos, se utilizaron:

- Análisis-síntesis: posibilita el procesamiento de la información a partir de la bibliografía consultada.

- Histórico-lógico: permite el estudio de los cambios previsibles en la demanda.

Dentro de los métodos empíricos se utilizó el análisis documental, pues fue necesario realizar un estudio de investigaciones a nivel internacional vinculado con los cambios previsibles en la demanda.

La investigación se realizó en el período de cuarentena debido a la pandemia de la COVID-19, por lo que no fue posible realizar un trabajo de campo profundo, ni intercambiar con visitantes al destino. Por ello y teniendo en cuenta el criterio de Sánchez et al (2020), para la obtención de información específica sobre la demanda potencial al destino Cuba, se realizó una encuesta online apoyada en el sitio web Google Form, el cual permitió tener un mayor alcance de la información sobre los clientes potenciales, en un menor tiempo del que se necesitaría normalmente a través de las vías tradicionales. Este tipo de encuesta ha sido utilizada en proyectos académicos, sondeos de opinión, estudios de mercado, medición de satisfacción, entre otros fines. 
Perelló (2009), citado en González et al. (2020), plantea que en la encuesta se recaban tanto aspectos objetivos (hechos), como aspectos subjetivos (opiniones y actitudes). Plantea además que las preguntas, se realizan para obtener información sobre datos comprobables referidos al propio sujeto encuestado o a personas, grupos o instituciones que el sujeto pueda conocer. Las preguntas sobre aspectos subjetivos abarcan todo un amplio espectro (opiniones, actitudes, intenciones, valores, juicios, sentimientos, motivos, aspiraciones, expectativas) que, aunque no son directamente comprobables, no por ello son menos reales y determinantes del comportamiento social.

El total de personas encuestadas fue de 7090, de diferentes países, los cuales figuran no solo como los principales mercados emisores de turismo a Cuba, si no que pueden constituir nuevos segmentos de demanda en la nueva normalidad post COVID-19.

\section{Resultados}

\subsection{Análisis teórico- conceptual}

\subsubsection{Demanda turística. Aspectos generales}

Nicolau (2011), citado en Rosabal (2020), define la demanda como un conjunto de visitantes que van a un lugar determinado por los atractivos que ofrece dicho lugar, acorde a las expectativas y disponibilidad de tiempo y dinero. Su análisis permite determinar las perspectivas de un lugar, el comportamiento preliminar a la visita y durante la visita, el retorno o regreso a su lugar de residencia y la relativa satisfacción del turista.

Por otro lado, Avellaneda y Juliana (2018) amplían el concepto agregando que la demanda turística siempre será el eje que mueve a la oferta turística generando el correcto funcionamiento del sistema turístico, ya que la demanda es quien condiciona la conformación de productos y de sus respectivos precios. Absolutamente toda la demanda de turistas tanto nacionales o internacionales tienen una motivación de ocio por la cual se desplazan a los diferentes lugares turísticos.

Desde la perspectiva del mercadeo convencional, la demanda turística puede ser definida de un modo semejante a cualquier otro tipo de demanda, no obstante, dentro del contexto del turismo, ésta tiene características que la diferencian, al estar asociada a las oportunidades, tiempo y recursos de los consumidores meta. Estas particularidades sustentan la categorización de la demanda planteada por Cooper, Fletcher, Fyall, et al. (2005) citados en Rosabal (2020) con el fin de conducir el proceso de planificación de la demanda:

- Demanda actual: se refiere al número actual de personas que participan en la actividad turística (turistas, viajeros o visitantes), es decir, que efectivamente viajan (consumidores reales).

- Demanda potencial: cuando estos consumidores son prospectos en los que se ha identificado una necesidad, motivación o interés asociado a un bien en particular, y que posiblemente viajarán.

- Demanda diferida: son las personas que no han podido viajar por algún problema en el entorno o en la oferta. A este grupo también pertenece el sector de la población que no puede viajar por ser un lujo demasiado.

Revista Internacional de Turismo, Empresa y Territorio, vol. 4, nº 2, 2020, pp. 158-177

https://www.uco.es/ucopress/ojs/index.php/riturem/index 
- No demanda: las personas que muestran una aversión a viajar o aquellas que simplemente no desean hacerlo.

Por otro lado, Martín (2009) considera que la demanda puede enfocarse al menos desde tres puntos de vista: económico (volúmenes de viajes o servicios turísticos que las personas están dispuestas a pagar a un precio específico en un momento determinado); geográfico (desde el punto de vista de la geografía humana, donde considera la demanda como los propios flujos turísticos actuales o potenciales); así como psicológico - sociológico (desde el punto de vista de la motivación y el comportamiento).

El principal objeto de estudio son las motivaciones de viaje que impulsan a un individuo a trasladarse de su lugar habitual de residencia para el consumo de un determinado producto turístico. Dependiendo de los segmentos de la demanda se conforman distintos tipos de productos turísticos, esto implica que cada producto se adecuará a las exigencias de esa demanda específica para garantizar su plena satisfacción (Jiménez y Peña 2017). Es preciso destacar que la "plena satisfacción" no existe, sin embargo, se podrían tener en cuenta los niveles de satisfacción.

Según Martín (2009), para caracterizar la demanda, debe tenerse en cuenta en principio el propio concepto de demanda. Esta surge, desde el punto de vista individual, a partir de que las personas tengan como mínimo la necesidad o interés de viajar, el tiempo disponible para realizar la actividad y, el nivel de renta adecuado o financiamiento para los gastos del viaje.

De acuerdo con Guevara (2011) y Cuevas y Hechavarría (2016), conocer la demanda y sus comportamientos de compra, de elección y de gastos es muy importante ya que permite hacer una investigación más precisa de lo que espera un visitante en determinado lugar, y aprovechar el análisis de esta información permite crear un panorama más claro de lo que se debe de hacer y a qué segmento dirigirse en el mercado.

\subsubsection{Cambios previsibles en la demanda turística}

Con la actual pandemia provocada por la COVID-19 cambiará de forma fehaciente el perfil de los visitantes. La actual situación es tan grave que diferentes investigadores opinan que ocurrirán cambios culturales profundos que pueden influir en un nuevo perfil del turista post COVID-19 caracterizado por: inseguridad, incertidumbre y austeridad. Estos tres aspectos generan nuevas necesidades que deben analizarse para ofrecer servicios que respondan a las nuevas demandas de los turistas (Wagner, 2020).

El grado de riesgo irá disminuyendo con el tiempo, a medida que se vaya controlando la crisis la seguridad sanitaria se afianzará. Según El Universal (2020), citado por Palomo Ortega, et al. (2020), muchas familias verán sus ingresos muy disminuidos; sin embargo, la renta disponible (o más bien la capacidad o poder de compra) es relativa, debido a que dependerán de los precios del mercado, y hay una gran posibilidad de que en el turismo reduzcan bastante. Además, Palomo, et al. (2020), afirma que "también es de esperar que las rentas de las familias se recuperen con el tiempo, la cuestión es cuánto tiempo...". (p. 164)

Ramperez (2020), expresa que según un estudio realizado por la agencia estratégica de marketing turístico Inturea "las necesidades y motivaciones de los viajeros en la era pos- 
COVID-19 evolucionan hacia un marco en el que la seguridad y la sensación de desconexión se posicionan sobre el precio o descubrir nuevos destinos".

En un estudio citado por Lalanza (2020), se muestran algunas características relacionadas con los viajes por diferentes grupos, en la etapa post COVID-19 (Tabla 1).

Tabla 1. Exigencias para los viajes post COVID-19.

\begin{tabular}{|c|c|c|c|}
\hline Parejas adultas & Familias con niños & Grupos de amigos & Viajeros Senior \\
\hline $\begin{array}{lcr}81 \quad \% & \text { muy } \\
\text { preocupados } & \text { por } \\
\text { las medidas } & \text { de } \\
\text { seguridad } & \\
\end{array}$ & $\begin{array}{l}73 \% \text { se queda cerca } \\
\text { de casa }\end{array}$ & $\begin{array}{l}66 \% \text { se moverá } \\
\text { dentro del territorio } \\
\text { nacional }\end{array}$ & $\begin{array}{l}72 \% \text { tienen en } \\
\text { cuenta la higiene }\end{array}$ \\
\hline $\begin{array}{l}42 \% \text { reserva con } \\
\text { semanas } \\
\text { antelación }\end{array}$ & $\begin{array}{l}15 \% \text { deciden } \\
\text { probar el camping o } \\
\text { la caravana }\end{array}$ & $\begin{array}{l}31 \% \text { se moverá en } \\
\text { vehículo propio }\end{array}$ & $\begin{array}{l}47 \% \text { apuesta por las } \\
\text { aerolíneas }\end{array}$ \\
\hline $\begin{array}{ll}82 \% & \text { quiere } \\
\text { desconectar } & \text { de la } \\
\text { rutina } & \end{array}$ & $\begin{array}{l}43 \% \text { contratarán } \\
\text { seguro } \\
\text { cancelación }\end{array}$ & $\begin{array}{l}91 \% \text { valora el } \\
\text { precio en la toma de } \\
\text { decisiones }\end{array}$ & $\begin{array}{l}35 \% \text { está dispuesto } \\
\text { a seguir conociendo } \\
\text { el mundo }\end{array}$ \\
\hline
\end{tabular}

Fuente. Lalanza (2020).

De acuerdo con un trabajo de la Universidad Oberta de Catalunya, el coronavirus hará que predomine un turismo familiar, en coche y a destinos de proximidad. Lo que producirá una corriente contra la masificación y a favor del turismo responsable. El turista será más sensato para elegir destinos cercanos que le ofrezcan más confianza y sensación de control (Feijoó, 2020).

Feijoó (2020) considera que "el turista preferirá estar en lugares abiertos y con poca gente después de haber vivido mucho tiempo dentro de sus hogares cumpliendo el confinamiento social, además de moverse en lo cotidiano en ambientes de grandes conglomerados urbanos". (p. 4)

Para Wagner (2020):

Algunos afirman que el transcurrir este contexto ha generado una mayor conciencia social, que propenderá a profundizar comportamientos ambientales y sociales sustentables, por lo que debiéramos suponer que el turismo post pandemia (enmarcado por la sindemia) se sentirá comprometido y afín con aquellas organizaciones que reflejen estos mismos valores de sustentabilidad. La responsabilidad social será un aspecto aún más valorado como también los prestadores y destinos que realicen y promuevan el cuidado del medio ambiente. (p. 28)

Para Feijoó (2020), el turismo enogastronómico y turismo rural cercano a los centros emisores, volverán de forma relativamente más rápida, al igual que el turismo de playa y el turismo de aventura. En definitiva, un Turismo alejado de la masificación. Esto nos lleva a pensar que contaremos con visitantes que buscarán más propuestas individuales, alejadas de las aglomeraciones, buscando mayor seguridad higiénico-sanitaria y que estará más comprometido con la sustentabilidad. 
Según Exceltur (2020), citado por Lalanza (2020), los meses de confinamiento vividos en los hogares, han causado una gran variedad de clientes que van desde los que desean vivir un momento de libertad, de conocer y de disfrutar el ocio y las vacaciones; a aquellos que aumentarán la cautela y serán menos propensos a viajar, y si lo hacen lo harán buscando destinos que ofrezcan seguridad.

No todo el mundo piensa de la misma manera y hay muchas personas con temor, pero dispuesta a viajar si hay un descuento tentador. Pero en general, se puede afirmar que durante un buen tiempo habrá un gran miedo al virus (Sotelo, 2020).

Por otro lado, abordando el proceso de decisión de reserva, Ramperez (2020), al referirse a un estudio realizado por la agencia estratégica de marketing turístico Inturea, advierte que se alarga y a la par se reduce el booking window ${ }^{5}$. El viajero demorará mucho más de lo normal en el proceso de decisión de compra, el cual busca una experiencia de viaje que le aporte sensación de estabilidad; no será el momento de buscar sorpresas, ni ir a sitios por primera vez.

Desde el punto de vista de la relación el visitante pos-COVID-19, Fojo (2020), afirma que estos van a estar muy sensibilizados con la seguridad, lo que supondrá costes; van a ser más responsables y procurarán que las empresas lo sean. "La concepción del cliente va a cambiar mucho y va a poner en valor a las empresas que trabajen de forma justa, solidaria y sostenible". (Fojo, 2020)

Es evidente que la crisis crea un escenario donde el visitante necesita la seguridad en su máximo esplendor, y organizaciones que deberán ofrecerla rediseñando destinos, los productos y los servicios con las medidas necesarias y la responsabilidad socioambiental (Wagner, 2020).

Según Wagner (2020):

Se estima que una vez que se abran las fronteras y que sea posible viajar, la gente tendrá miedo de hacerlo: hacer la fila para hacer el check-in, subir a un avión, tomar un transfer, encender el aire acondicionado, visitar un museo, recorrer un mercado de artesanías, contratar una excursión, etc., serán actividades percibidas como muy riesgosas. (p.27)

\subsection{Análisis de las encuestas}

Los visitantes encuestados poseen nacionalidad argentina $(24.50 \%)$, belga $(0.98 \%)$, boliviana $(1.96 \%)$, brasileña $(0.98 \%)$, chilena $(2.94 \%)$, colombiana $(1.96 \%)$, costarricense (2.94\%), cubano-americana (1.96\%), dominicana (4.90\%), ecuatoriana (3.92\%), estadounidense $(3.92 \%)$, española $(0.98 \%)$, hondureña $(0.98 \%)$, mexicana $(37.25 \%)$, nicaragüense $(1.96 \%)$, paraguaya $(1.96 \%)$, peruana $(4.90 \%)$ y polaca $(0.98 \%)$. La muestra está conformada por clientes de ambos sexos, representando el femenino el $71.56 \%$ y el masculino el $28.44 \%$, así como por un rango de edad que va desde los 18 hasta los mayores de 66 años.

Aproximadamente el $24 \%$ de los encuestados no tienen decidido si viajarían este año hacia el exterior si tuvieran la oportunidad, el $35 \%$ si lo haría y el $41 \%$ restante están decidido

\footnotetext{
${ }^{5}$ Booking Windows o ventana de reserva es la antelación con la que se realiza una reserva, o el período de tiempo que transcurre entre el momento en el que se realiza la reserva y el registro en el hotel.

Revista Internacional de Turismo, Empresa y Territorio, vol. 4, $\mathrm{n}^{0}$ 2, 2020, pp. 158-177

https://www.uco.es/ucopress/ojs/index.php/riturem/index
} 
a no hacerlo por diversos motivos, siendo el riesgo al contagio por la COVID-19 el más representativo (Figura 1).

Figura 1. Motivos para no viajar en 2020.

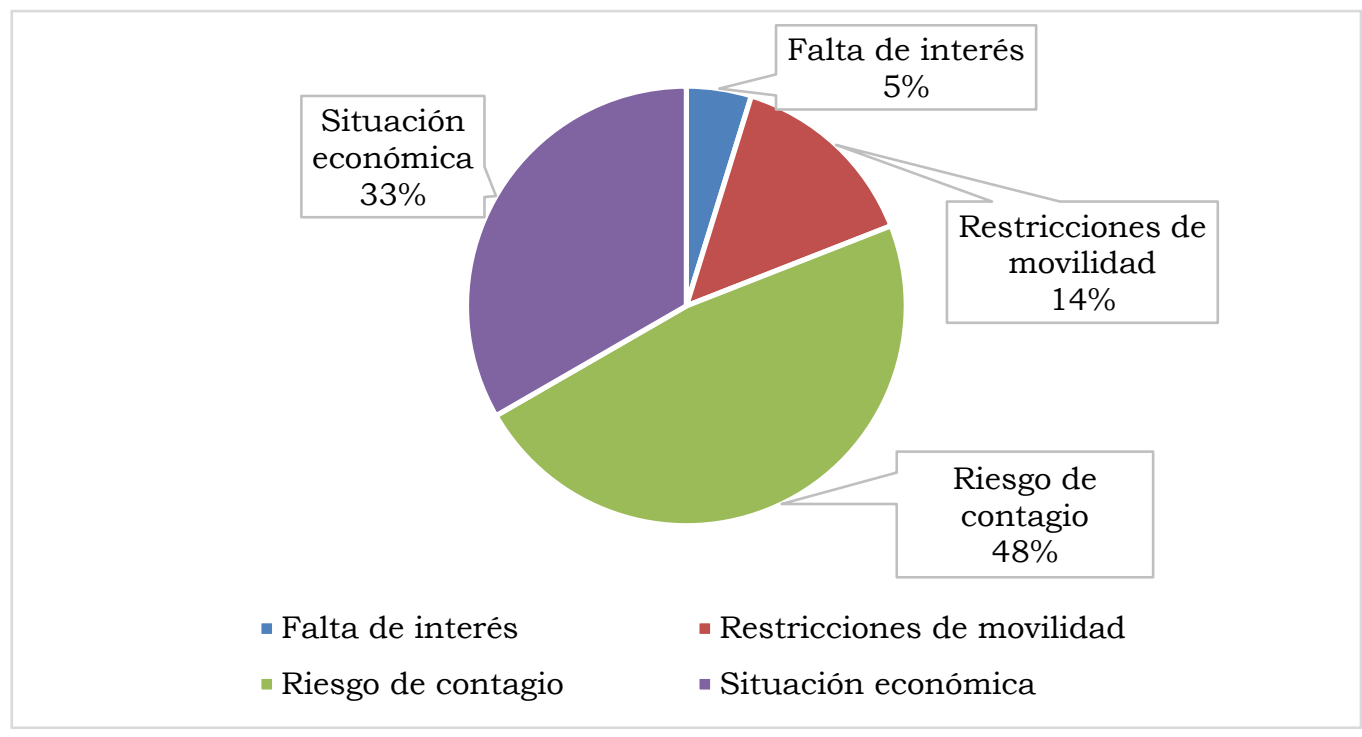

\section{Elaboración propia}

Todos los encuestados que se sienten seguros de viajar entre noviembre y diciembre del presente año (2020) visitarían el destino Cuba, al igual que, aproximadamente, más del $80 \%$ de los que lo harían antes que culmine el año 2021. Por su parte, menos del $20 \%$ de los que viajarían en 2021 aún no deciden si visitan la isla caribeña. Existe un por ciento mínimo de encuestados que no viajarían al destino (aproximadamente el $3 \%$ ) pero tampoco sienten seguridad para realizar viajes a otros lugares, ya sea porque no tengan decidido la fecha o porque estén en la espera de una vacuna para erradicar el riesgo de contagio por la COVID-19.

En el caso que los encuestados viajasen a Cuba, las motivaciones principales son conocer sobre la cultura $(43.13 \%)$, las playas $(24.50 \%)$ y las costumbres $(13.72 \%)$, tal y como se muestra en la Figura 2.

Figura 2. Motivaciones para viajar a Cuba.

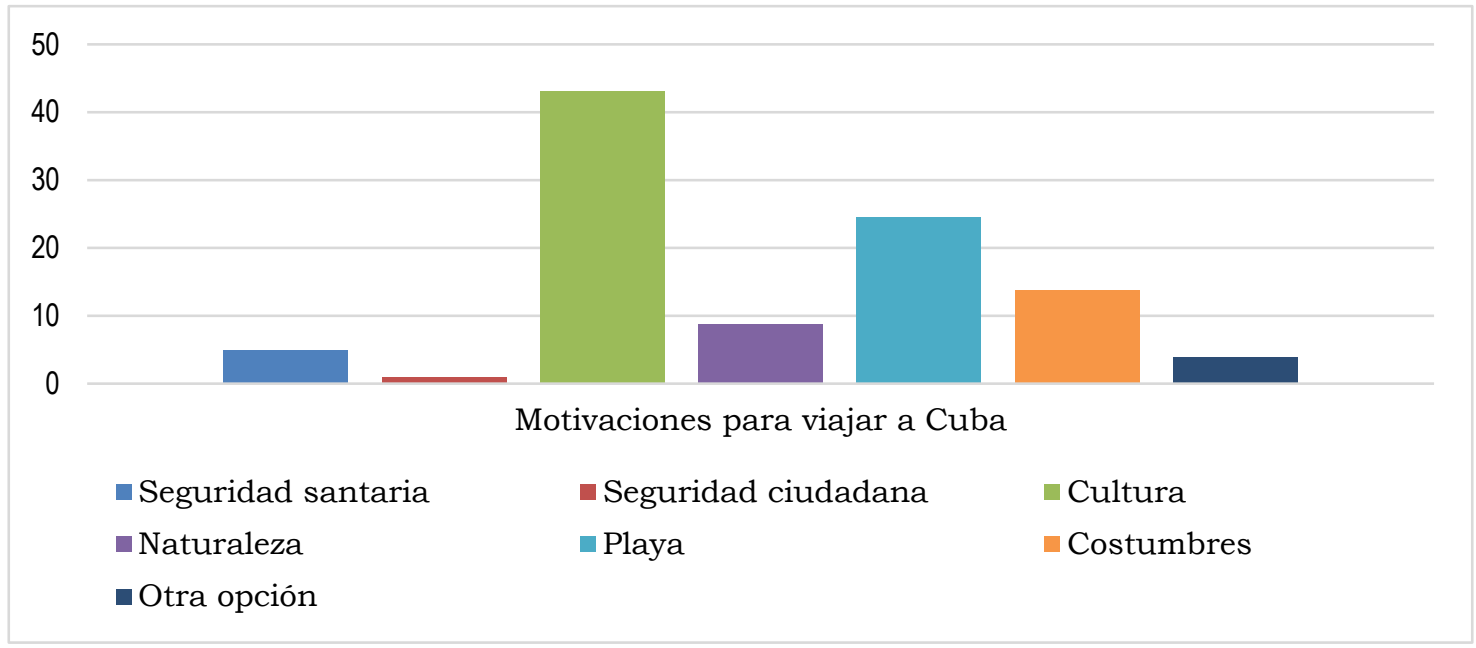

Revista Internacional de Turismo, Empresa y Territorio, vol. 4, nº 2, 2020, pp. 158-177 https://www.uco.es/ucopress/ojs/index.php/riturem/index 


\section{Fuente: Elaboración propia}

Las vías por las cuales los encuestados buscan información para organizar sus viajes son varias, sin embargo, vale la pena señalar que, las redes sociales, los agentes de viajes, y los Amigos y familiares fueron las más seleccionadas. Por su parte, hubo un por ciento mínimo de encuestados que utilizaron otras vías en la búsqueda de información diferentes a las ofrecidas, tales como guías turísticas (libros), otras páginas webs y blogs comunitarios (Tabla 2).

Tabla 2. Vías por las cuales obtienen información para la realización del viaje.

\begin{tabular}{|l|l|}
\hline Vías para la búsqueda de información & Fr (\%) \\
\hline Experiencia personal de viajes anteriores & 11.76 \\
\hline Amigos y familiares & 16.66 \\
\hline Agentes de viajes & 25.49 \\
\hline Páginas webs del destino & 11.76 \\
\hline Redes sociales & 30.39 \\
\hline Otra vía & 3.92 \\
\hline
\end{tabular}

Fuente: Elaboración propia

$\mathrm{Al}$ relacionar las dos variables que se encuentra en la Figura 3, se puede llegar a varias conclusiones que, aunque puedan parecer obvias algunas de ellas, es significativo haber podido demostrarlas con el estudio. Los que organizarían su viaje de forma independiente generalmente utilizarían, con mayor frecuencia, la mayoría de las vías para obtener información sobre el mismo.

Es muy notable que la utilización de los agentes de viajes para informarse en la organización del viaje está determinada por la manera en que este se organiza, los encuestados que utilizarían una agencia de viaje para la organización de su viaje, también la utilizarían para obtener la información necesaria en su organización. Se debe destacar, que mientras más se deposita la responsabilidad en una misma agencia, más la información obtenida depende de esta.

Las vías para obtener información por internet a través de las redes sociales son más o menos igualmente utilizadas por los encuestados sin importar la forma de organización del viaje, excepto de los que lo hacen de forma independiente, que lo utilizarían con mayor frecuencia. Los que organizarían su viaje de otra manera (generalmente contratando algunos servicios de forma independiente y otros mediante alguna agencia de viajes) utilizarían solo las agencias de viajes y las redes sociales para obtener información en la organización del viaje. 
Figura 3. Relación entre la manera en que organizó el viaje y las vías utilizadas para obtener información en la organización del viaje (\%).

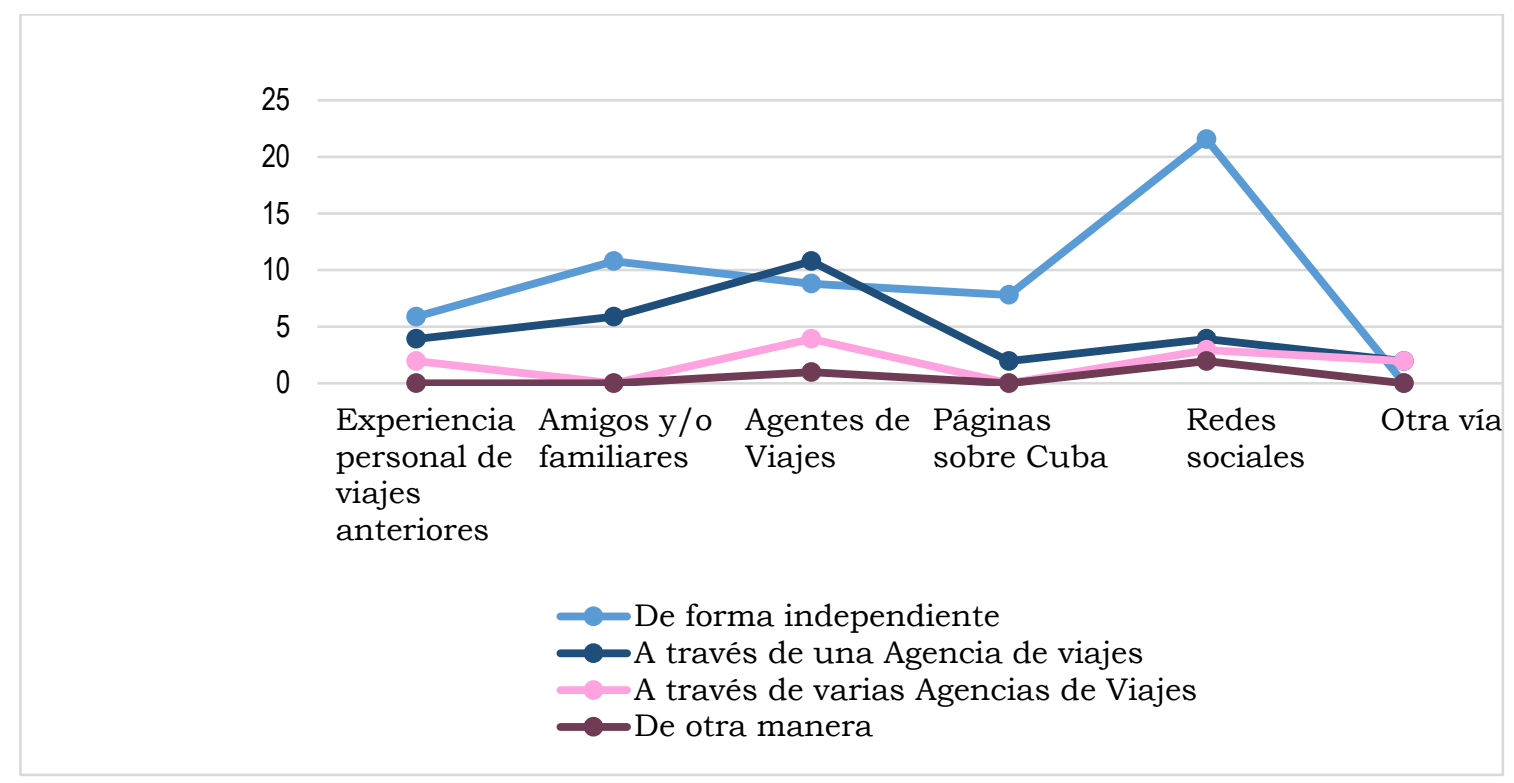

Fuente: Elaboración propia

En cuanto a la relación entre las variables que se muestran en la Figura 4 se puede analizar como la selección de 2 a 3 días de duración del viaje fue seleccionada prácticamente igual por los encuestados sin importar la compañía. Los que viajarán en pareja o con amigos prefieren, en mayor medida, una semana de duración para el viaje. Las frecuencias de selección de la duración del viaje por más de una semana disminuyen sin importar la cantidad de personas con las que se realice el mismo.

Figura 4. Relación entre la duración del viaje y la compañía para el mismo (\%).

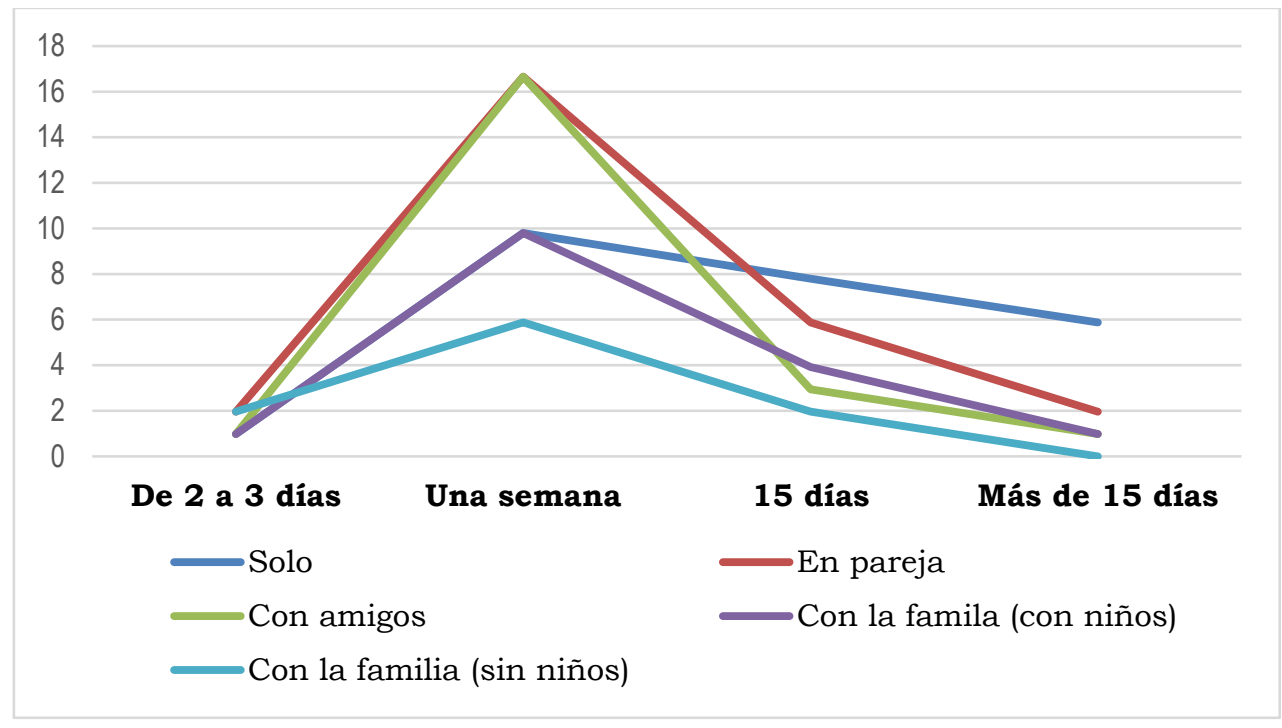

Fuente: Elaboración propia 
La siguiente variable está referida a los procesos que, durante el viaje, el encuestado cree que hay más riesgos de contraer el virus. Tal y como se muestra en la Tabla 3, destacan como los más seleccionados el transporte terrestre y los lugares de interés turísticos.

Tabla 3. Procesos de mayor riesgo para el contagio del virus

\begin{tabular}{|l|c|}
\hline Procesos de mayor riesgo para el contagio del virus & Fr (\%) \\
\hline Transporte terrestre & 45.09 \\
\hline Transporte aéreo & 26.47 \\
\hline Restaurantes & 6.86 \\
\hline Establecimientos de hospedaje & 3.92 \\
\hline Lugares de interés turístico & 17.64 \\
\hline
\end{tabular}

Fuente: Elaboración propia

Por su parte las otras dos variables están relacionadas con la selección de tipo de transporte y alojamiento que utilizaría en el destino (Tabla 4). Destacan como los más seleccionados el transporte de agencia de viajes (30.39\%) y los hoteles (50\%).

Tabla 4. Tipo de transporte y hospedaje en el destino.

\begin{tabular}{|l|c|}
\hline Tipo de transporte a utilizar en el destino & Fr (\%) \\
\hline Vehículo arrendado & 28.43 \\
\hline Servicio público & 16.66 \\
\hline Transporte de agencias de viajes & 30.39 \\
\hline Transporte privado & 21.56 \\
\hline Otra vía & 2.94 \\
\hline Tipo de hospedaje a utilizar en el destino & Fr (\%) \\
\hline Hotel & 50 \\
\hline Hostal & 14.70 \\
\hline Apartamento de renta privada & 27.45 \\
\hline Casa de familiares o amigos & 7.84 \\
\hline
\end{tabular}

Fuente: Elaboración propia

Desde otro punto de análisis, los encuestados que consideran que durante el viaje existe mayor riesgo de contraer el virus en los medios de transporte terrestre y en los establecimientos de hospedaje, utilizarían los medios de transporte de las agencias de viajes y los hoteles respectivamente para viajar y hospedarse en el destino.

La siguiente variable está referida a la principal prioridad a la hora de realizar un viaje (Tabla 5). Destacan como las más seleccionadas por los encuestados los protocolos de higiene (30.39\%), la certificación “COVID FREE” (18.62\%) y la flexibilización de cambio de viaje y destino $(15.78 \%)$. 
Tabla 5: Prioridad a la hora de realizar un viaje.

\begin{tabular}{|l|c|}
\hline Prioridad a la hora de realizar un viaje & Fr (\%) \\
\hline Protocolos de higiene & 30.39 \\
\hline Certificación "COVID FREE” & 18.62 \\
\hline Flexibilización de cambio de viaje y destino & 15.68 \\
\hline Presupuesto & 13.72 \\
\hline $\begin{array}{l}\text { Atención 24x7 antes, durante y después del } \\
\text { viaje }\end{array}$ & 6.86 \\
\hline Lugares no muy concurridos & 14.70 \\
\hline
\end{tabular}

Fuente: Elaboración propia

Al analizar esta variable con relación a la edad, como se muestra en la figura 5, se puede señalar que, más del $50 \%$ de los encuestados mayores de 65 años de edad tienen como principal prioridad a la hora de realizar un viaje la existencia y cumplimiento de los protocolos de higiene, así como la flexibilización de cambio de viajes y destinos. Los encuestados de entre 26 y 45 años y los de entre 18 y 35 son los que menos priorizan la certificación COVID FREE y el presupuesto respectivamente como requisito para viajar. Solo los encuestados de entre 18 y 45 años tienen como prioridad para viajar la atención $24 \times 7$ antes, durante y después del viaje. Los lugares no muy concurridos son tomados en cuenta por todos los encuestados a la hora de realizar el viaje, sin importar su edad.

Al analizar la variable con relación al sexo se puede señalar que los encuestados del sexo femenino toman en cuentan, en mayor proporción, todas las prioridades para viajar que los del sexo masculino.

Figura 5. Relación entre la Edad y las prioridades a la hora de realizar el viaje (\%).

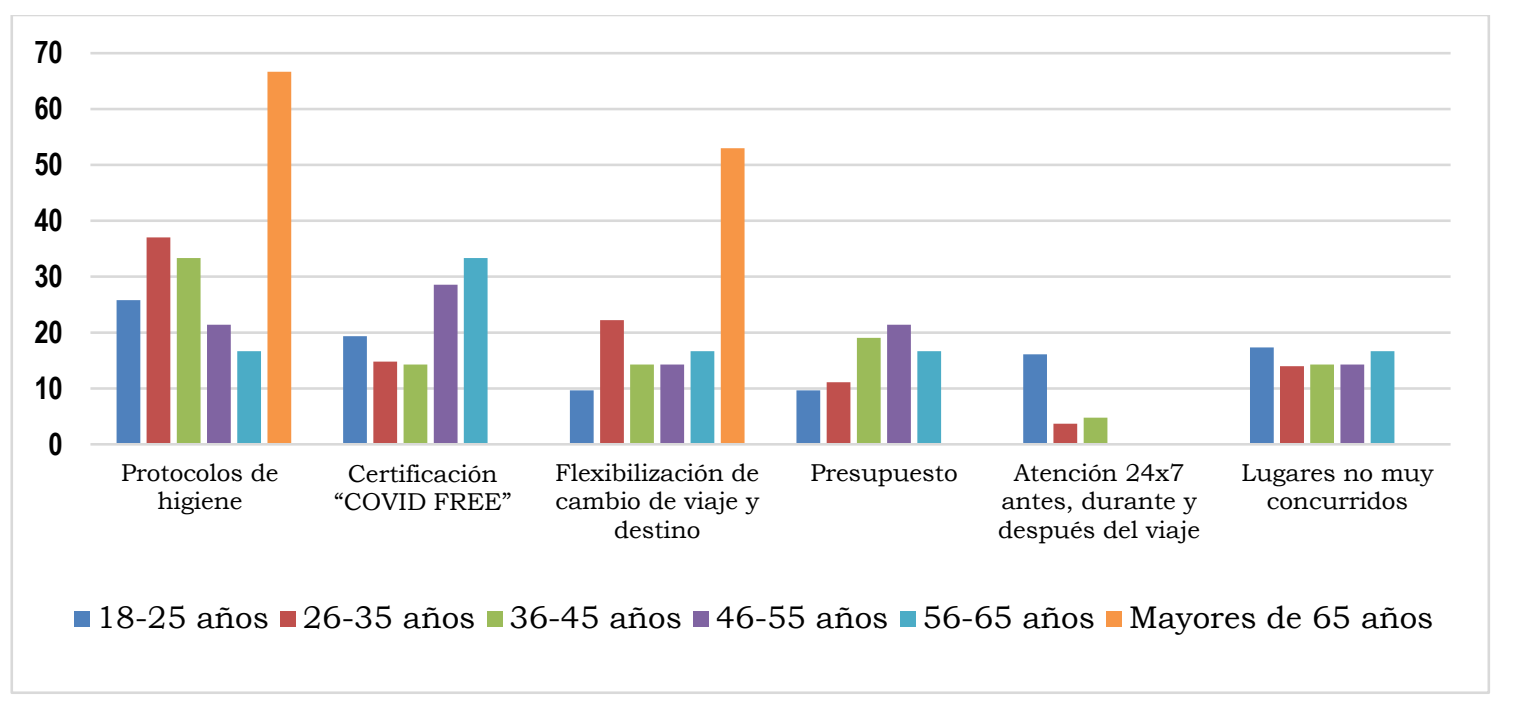

Fuente: Elaboración propia

Otra de las variables está relacionada con el tipo de turismo que al encuestado le gustaría hacer después de la crisis. Tal y como se muestra en la Tabla 6, destacan entre las más 
seleccionadas, el turismo de naturaleza $(33.33 \%)$, el de sol y playa $(24.50 \%)$ y el rural (16.66 $\%)$.

Tabla 6. Tipo de turismo que al encuestado le gustaría hacer después de la crisis.

\begin{tabular}{|l|c|}
\hline $\begin{array}{c}\text { Tipo de turismo que al encuestado le } \\
\text { gustaría hacer después de la crisis }\end{array}$ & Fr $(\%)$ \\
\hline Sol y playa & 24.50 \\
\hline Naturaleza & 33.33 \\
\hline Urbano & 1.96 \\
\hline Cultural & 12.74 \\
\hline Rural & 16.66 \\
\hline Crucero & 0.98 \\
\hline Náutico & 9.80 \\
\hline
\end{tabular}

Fuente: Elaboración propia

$\mathrm{Al}$ analizar esta variable con relación a la edad, como se muestra en la figura 6 , se puede señalar que, a los encuestados menores de 35 años son los que más les gustaría hacer turismo rural y de sol y playa. Tanto el turismo de naturaleza como el náutico, son seleccionados, con mayor frecuencia, por los encuestados mayores de 65 años. Realizar turismo urbano después de la crisis solo le interesa a una muestra mínima de encuestados de entre 18 y 35 años de edad, así como el de crucero a una de entre 56 y 65 años. Los que poseen entre 36 y 45 años prefieren el turismo de ciudad ante otras opciones. La frecuencia de selección del turismo náutico aumenta de conjunto con la edad.

Figura 6. Relación entre la edad y el tipo de turismo que prefieren los encuestados (\%).

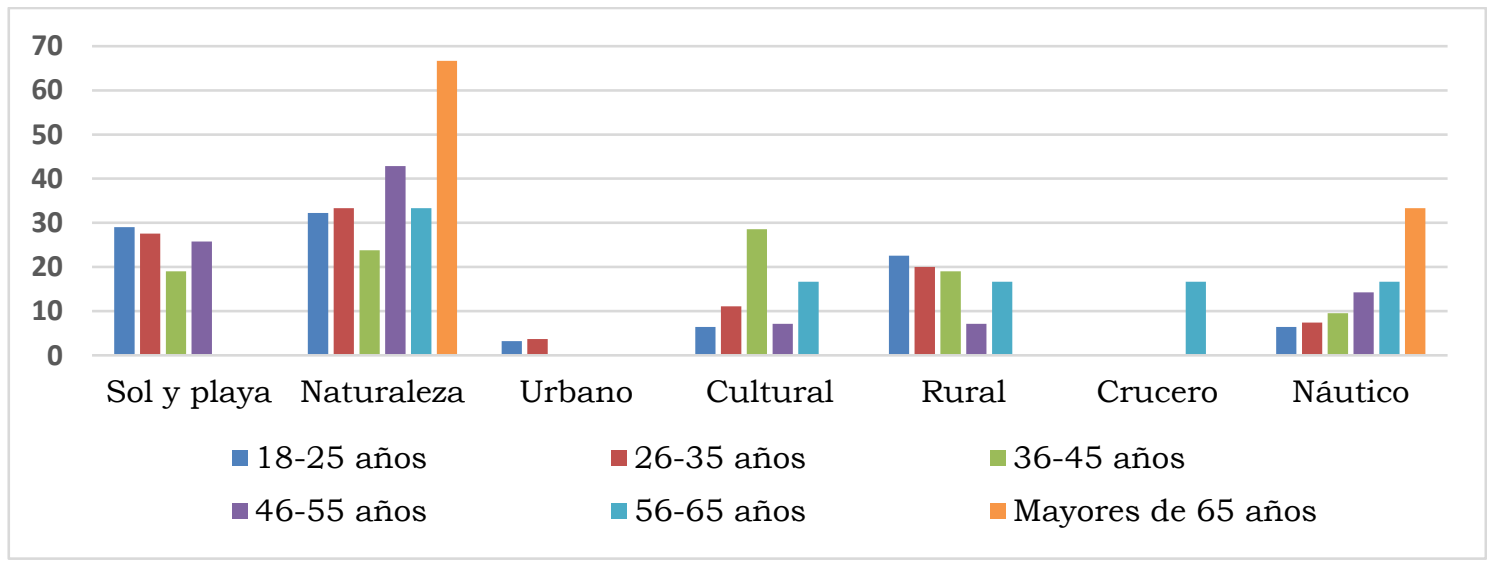

Fuente: Elaboración propia 
Al analizar la variable con relación al sexo se puede señalar que los encuestados del sexo femeninos son los que prefieren, con mayor frecuencia, todos los tipos de turismo solo a excepción de la actividad de cruceros turísticos, representativa por parte del sexo masculino.

La última variable que analizar está vinculada a las medidas que ayudan a prevenir el riesgo de contagio del virus en los destinos turísticos, las más importantes para los encuestados fueron el distanciamiento (100\%), el uso de mascarillas (100\%) y de gel hidroalcohólico antibacterias (98\%), así como la desinfección del calzado (98\%).

\section{Conclusiones}

A partir de los resultados presentados anteriormente se pueden arribar a las siguientes conclusiones:

- La nueva economía del turismo se verá reinventada por los modos de hacer de los diferentes gestores, así como de los gustos y preferencias de la demanda.

- Un tanto por ciento significativo de los encuestados que visitarían el destino Cuba lo haría antes que finalice el año 2021.

- Las motivaciones principales de los viajes son conocer la cultura y disfrutar las playas.

- Las vías por las cuales los encuestados buscan información para organizar sus viajes son varias, pero, sin embargo, vale la pena resaltar las redes sociales y los agentes de viajes

- Las formas más comunes de organizar el viaje son de forma independiente y a través de una agencia de viajes.

- Las principales prioridades a la hora de realizar un viaje son la existencia de los protocolos de higiene y la certificación "COVID FREE".

- El tipo de turismo que a los encuestados les gustaría realizar en la nueva normalidad varía en función de sus edades, pero las más seleccionadas fueron, por este rorden, el motivado por el sol y playa, por la naturaleza y por el medio rural.

\section{Referencias}

Avellaneda, Y. y Juliana, K., 2018. Demanda turística. Recuperado de: https://repositorio.ucsg.edu.ec.

Cuevas, C. y Hechavarría, L. (2016). Coherencia de la oferta turística de Cuba y la demanda turística estadounidense. Retos Turísticos, 15 (1), enero-abril.

Díaz-Canel, M., y Núñez, J (2020). Gestión gubernamental y ciencia cubana en el enfrentamiento a la Covid-19. Anales de la Academia de Ciencias de Cuba, 10 (2), 1 - 10.

Feijoó, J. L. (2020). Cómo se recuperará el turismo después de la pandemia. En, J. L. Feijoó, M. Wagner, Tendencias y reflexiones / Sur, pandemia y después. (pp. 3). Universidad de Belgrano. http://repositorio.ub.edu.ar/handle/123456789/8951 
Fojo, G. (2020). Los test masivos son prioritarios para reactivar al sector turístico. En, J. L. Feijoó, M. Wagner, Tendencias y reflexiones / Sur, pandemia y después. (pp. 8-9). Universidad de Belgrano. http://repositorio.ub.edu.ar/handle/123456789/8951

González Peraza, B. de la C., Quintana Soto, M., Hernández Flores, Y., \& Velasteguí López, L. E. (2020). Diseño de un producto turístico para los viajeros procedentes de la Comunidad Autónoma de Galicia a La Habana. Conciencia Digital, 3(4), 45-61. https://doi.org/10.33262/concienciadigital.v3i4.1424

Guevara, N. (2011). Demanda Turística en la Comunidad de Madrid: Análisis y Modelos de Detección de Variables Significativas. (Tesis doctoral). Madrid: Universidad Rey Juan Carlos.

Hernández, R., Fernández, C. y Baptista, M. (2014). Metodología de la investigación. Sexta Edición. México: Mc Graw Hill Education.

Hernández Flores, Y., Rodríguez González, M., y Ayala Castro, H. (2020). Diseño del escenario más probable de la OSDE Viajes Cuba al año 2025. Revista científica de Ecociencia, 7 (3), 1-29. Recuperado de: http://revistas.ecotec.edu.ec/index.php/ecociencia/article/view/363

Higgins-Desbiolles, F. (2020). Socialising tourism for social and ecological justice after COVID-19. Tourism Geographies, 6688. https://doi.org/10.1080/14616688.2020.1757748

Jiménez, M. y Peña, A.R. (2017). La demanda turística internacional: recuperación de la crisis y turismo, una primera aproximación al caso español. Investigaciones Regionales, 38, 47 66.

Lalanza, S. M. (2020). Conclusiones: el futuro del turismo. Entender al nuevo turista. En, S. M. Lalanza, Claves para entender el turismo pos-COVID-19. (pp. 23). OBS Business School. https://obsbusiness.school/es/informe-de-investigacion/informe-obs-claves-paraentender-el-turismo-pos-covid-19

Martín, R. (2009). Principios, organización y prácticas para el turismo. La Habana: Félix Varela.

Palomo, G., Navarro, E., Cerezo, A., Torres, E. (2020). Turismo poscoronavirus, ¿una oportunidad para el poscrecimiento? En, M. Simancas Cruz, R. Hernández Martín, N. Padrón Fumero, Turismo pos-COVID-19. Reflexiones, retos y oportunidades. (pp. 164). Cátedra de Turismo Caja Canarias - Ashotel de la Universidad de La Laguna. http://riull.ull.es/xmlui/handle/915/20451

Rodríguez, J. (12 de mayo de 2020). El impacto de la COVID-19 en el turismo mundial: el escenario de Cuba. Consultado el 2 de julio de 2020. Recuperado de: https://www.cuabahora.cu/economia/el-impacto-de-la-COVID-19-en-el-turismomundial-el-escenario-de-Cuba.html

Rosabal Viltres, H. (2020). Caracterización de la demanda internacional para las casas veraniegas del Grupo Empresarial Hotelero Islazul S.A. (Tesis de licenciatura). Facultad de Turismo, Universidad de La Habana. 
Ramperez, L. (2020). El viajero pos-COVIS-19: complica el proceso de compra y reduce el Booking Window. Hosteltur. https://www.hosteltur.com/comunidad/nota/022614_elviajero-post-covid-19-complica-el-proceso-de-compra-y-reduce-el-booking-window.html

Sánchez Huarcaya, A., Revilla Figueroa, D., Alayza Degola, M., Sime Poma, L. y Mendívil Trelles de Peña, L. (2020)._Los métodos de investigación para la elaboración de las tesis de maestría en educación. Pontificia Universidad Católica del Perú, Facultad de Educación.

http://blog.pucp.edu.pe/blog/maestriaeducacion/2020/07/23/los-metodos-deinvestigacion-para-la-elaboracion-de-las-tesis-de-maestria-en-educacion/

Sotelo, P. N. (2020). Posibles escenarios turísticos tras el covid-19. En, J. L. Feijoó, M. Wagner, Tendencias y reflexiones / Sur, pandemia y después. (pp. 20). Universidad de Belgrano. http://repositorio.ub.edu.ar/handle/123456789/8951

Wagner, M. (2020). La calidad como estrategia en clave de pandemia. En, J. L. Feijoó, M. Wagner, Tendencias y reflexiones / Sur, pandemia y después. (pp. 27-28). Universidad de Belgrano. http://repositorio.ub.edu.ar/handle/123456789/8951 